\title{
Compansation of Electrical Voltage in Distribution System by Dynamic Voltage Restorer \\ May Phone Thit
}

\author{
Soe Soe Ei Aung \\ Department of Electrical Power Engineering \\ Yangon Technological University \\ Yangon,Myanmar \\ soesoeeiaung80@gmail.com
}

\begin{abstract}
Electrical ac power systems consist of generation systems, transmission and distribution networks. The large three phase industrial loads at various distribution and transmission voltages as well as single-phase residential and commercial loads are supplied by the networks. Nowadays, the power quality such as voltage sags/swell, transient interrupts and harmonic distortions in sinusoidal waveforms are concerned with most of the electrical loads. The power quality problems such as voltage sags, swells and harmonics are caused by the widespread using of power electronics devices in power system. In this paper, electrical voltage sags/swells of power quality problems are considered because this problem is one of the most severe disturbances to the industrial equipment of distribution system. Thus, mitigation of these voltages in distribution system is necessary. So, series connected power electronics based device such as Dynamic Voltage Restorer (DVR) is chosen to compensate these voltage for mitigating quickly the voltage sag/swell in the system and restoring the load voltage to the nominal value. For case study, Myaungtagar industrial zone is chosen due to furnaces and large motor drives that cause the common problems such as voltage sag/swell in this system. In this paper, performance analysis of voltage sag/swell compensation of power distribution system with Dynamic Voltage Restorer (DVR) under various fault conditions is carried out. The proposed configuration model uses MATLAB/SIMULINK and the performance of voltage compensation and restoration of load voltage to the nominal value with DVR under various fault conditions is verified by the simulation results.
\end{abstract}

Keywords - Voltage compensation, Voltage sag, Voltage swell, Dynamic Voltage Restorer

\section{INTRODUCTION}

The uninterrupted power supply with smooth sinusoidal voltage at the contracted magnitude level and frequency should be supplied to the customers by power distribution systems. However, in power distribution systems, there are numerous nonlinear loads that significantly affect the quality of power supplies. The waveform of the supply system with loss purity of sinusoidal will occur due to the nonlinear loads. Thus, many power quality problems are produced at the ends. [1].

In modern distribution system, due to the voltage drop in feeders and transformers, faults, use of unbalanced lagging power factor consumer loads, various kinds of disturbances, the power quality problems at point of common coupling (PCC) occur. Some of the voltage-related power quality problems are surges, flickers, sags, swells, notches, fluctuations, voltage imbalance, waveform distortion, and so on. For injecting the voltage of required magnitude and frequency and restoring the voltage across the loads to protect

\author{
Department of Electrical Power Engineering \\ Yangon Technological University \\ Yangon,Myanmar \\ mayphonethit@gmail.com
}

the sensitive loads from these voltage quality problems, active series compensators are extensively used. Solid-state synchronous series as multi-leveled equations, graphics, and tables are not prescribed, although the various compensators (SSCs) and dynamic voltage restorers (DVRs) are known as active series compensators. In this paper, DVRs is used to compensate the electrical voltage of the distribution system [2].

The DVR is a series connected power electronic device. It can protect the system against the bulk of these disturbances, such as voltage sags and swells related to remote system faults. A DVR can compensate for these voltage excursions, provide the continuous supply. Thus, DVR can control the sag detection, transient and steady-state condition of the injected voltage, and maintain the voltage regulation. The typical power quality disturbances are voltage sags, voltage swells, interruptions, harmonics and transients. Among the disturbances, voltage sag is considered the most severe since the sensitive loads are very susceptible to temporary changes in the voltage [3].

\section{Voltage Regulation And SAG/Swell IN DISTRIBUTION SYSTEM}

In modern power systems, the equipment operates with standard voltages. When certain load current with any power factor is drawn from its output leads, the voltage drop that takes place inside a transformer is necessary to quantify. This drop is expressed as a ratio of the terminal voltage and called the voltage regulation [5]. At distribution level, the voltage regulation should be within $\pm 10 \%$ of nominal voltages.

$$
\text { Voltage Regulation }=\frac{\left|\mathrm{v}_{\mathrm{nl}}\right|-\left|\mathrm{v}_{\mathrm{fl}}\right|}{\left|\mathrm{v}_{\mathrm{nl}}\right|}
$$

\section{A. Voltage Sag:}

At the power frequency with durations from 0.5 cycles to $1 \mathrm{~min}$, the voltage drops between 0.1 and $0.9 \mathrm{pu}$ in rms voltage is called the voltage sag [5]. The voltage signal with sag waveform is shown in Fi. 1. Sometime, voltage sag last for long duration. This prolonged low voltage profile is referred as 'under-voltage'. Voltage sag is further divided in three categories: instantaneous, momentary and temporary sags respectively [6].

In distribution system, voltage sag conditions can be occurred because of the occurrence of faults in power system, excessive loads, starting of large induction motors, the electric furnaces and electrical faults. 


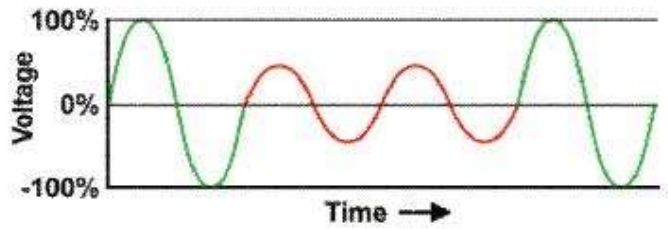

Fig. 1. Voltage Signal with sag waveform [5]

\section{B. Voltage Swell}

Voltage swell is defined as the voltage increasing between 1.1 and $1.8 \mathrm{pu}$ in rms voltage at the power frequency for durations from 0.5 cycle to $1 \mathrm{~min}$ [5]. This voltage condition is shown in Fig. 2. The prolonged high voltage profile is referred as 'over-voltage'. Voltage swell is subdivided as: instantaneous swell, momentary swell, temporary swell [6].

In distribution system, due to capacitor bank switching, turn on of lightly loaded lines and sudden turn off of large loads, single line to ground fault (SLG), and voltage swell conditions can be occurred which results in voltage rise in un-faulted phases and loose connection of neutral wire. Thus, breakdown of insulation, overheating of electrical equipment and damage to electronic equipment can be caused due to voltage swell.

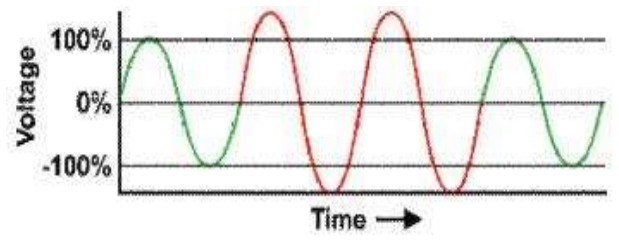

Fig. 2. Voltage Signal with swell waveform [5]

\section{Voltage Compensation Methods}

Power devices have proven to be an attractive solution to the voltage problem. For improving the performance of the power system, mitigation devices such as DVR (Dynamic Voltage Restorer), UPS (Uninterruptible Power Supply), DSTATCOM (Distribution Static Synchronous Compensator) and so on to be installed at the system-load interface.

D-STATCOM and UPS is more expensive than DVR. In UPS, a lot of maintenance which may be due to problems of battery leakage and replacement are necessary to be done. DVR has simple control and less maintenance than DSTATCOM. And it is smaller in size and is a better power effective device as compared to others link UPS, and DSTATCOM. Therefore, in this paper emphasize on the DVR for voltage sag/swell compensation.

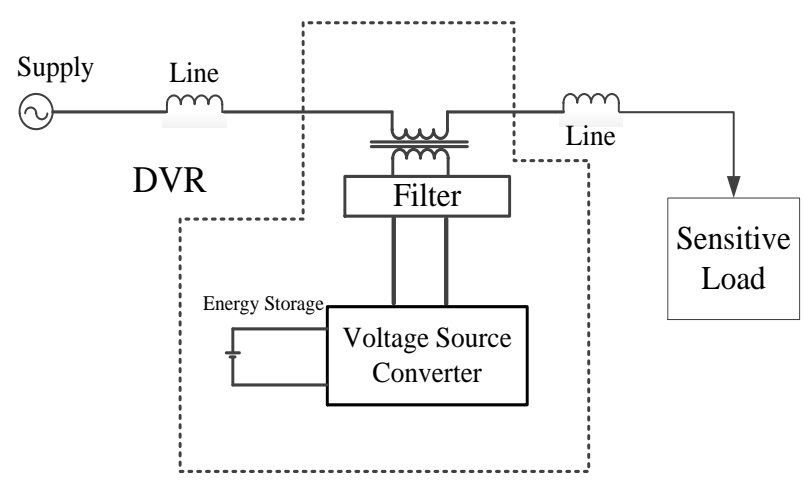

Fig.3. Schematic diagram of dynamic voltage restorer [3]

\section{CONSTRUCTION AND OPERATION OF DVR}

At distribution level, DVR is a custom power device. The DVR is implemented using voltage source converter (VSC) with fast switching power semiconductor devices such as IGBT or IGCT. VSC in series with distribution feeder inject the voltage and this voltage injection is controlled by using Hysteresis control technique. And then, by using IGBT which has the rapid switching capability, voltage problems such as sag and swell can be dynamically compensated.

To inject voltage of required magnitude and frequency, the DVR which is a series connected power electronic device is used. The basic structure of a DVR is shown in Fig 3. It contains the following components-

- Voltage Source Converter (VSC)

- DC storage unit

- Filter circuit

- Series Transformer

\section{A. Voltage Source Converter (VSC)}

A VSC is a power electronic system consists of a storage device and switching devices. It can generate a sinusoidal voltage at any required frequency, magnitude, and phase angle. In the DVR application, the VSC is used to temporarily replace the supply voltage or to generate the part of the supply voltage which is missing [7]. To convert the $\mathrm{DC}$ input to $\mathrm{AC}$, the solid state switches like IGBT's or GTO's consists in VSC. For compensating the decreasing voltage in the supply, it is used to inject the AC voltage. The switches of the VSC are operated with the gate pulses supplied from the drive circuits via PWM or hysteresis controller [3].

\section{B. DC Storage Unit}

Batteries, capacitors, flywheel, or super magnetic energy storage (SMES) consists in the storage unit. During sag condition, energy is taken from the faulted grid supply for internal storage capacity of DVR. This configuration is shown in Fig. 3. Here, to convert the AC voltage from the grid to DC voltage which is required for the VSC, a rectifier is used [4].

\section{Filter Circuit}

A filter circuit consists of an inductor and capacitor. It is used to filter out the switching harmonic components from the injected voltage. To filter the harmonics in the output voltage of VSC, an LC filter is connected at the output of the VSC. Filter has a small rating approximately $2 \%$ of the load MVA connected to delta-connected tertiary winding of the injection transformer [1].

\section{Series Transformer}

A series transformer is used to connect the DVR with the distribution feeder. In case of three phase system, three single phase transformers are used to connect the DVR with the power network [4].

\section{E. The DVR Operation Modes}

The DVR uses to measure the missing voltage by using control unit, inject the dynamically controlled missing voltage in series to the line and then maintain the load voltage during sag condition. In this sag condition, the phase angle and 
amplitude of the injected voltages are variable. Thus, the active and reactive power exchange between the DVR and the distribution system are necessary to control. Generally, the operation of the DVR can be categorized into three operation mode: protection mode, standby mode (during steady state) and injection mode (during sag)[7].

\section{INDUSTRIAL DISTRIBUTION SYSTEM UNDER STUDY}

In this paper, the case study area is chosen at Myaungtagar industrial distribution zone. It has seventeen feeders. Eight feeders are connected with $230 \mathrm{kV} / 33 \mathrm{kV} 100 \mathrm{MVA}$ step-down transformer, five feeders are connected with $230 \mathrm{kV} / 33 \mathrm{kV}$ 60MVA step-down transformer, and four feeders are connected with $230 \mathrm{kV} / 33 \mathrm{kV}$ 150MVA transformer respectively.

This paper is emphasized on 100MVA transformer side in which the power quality problem occurs due to industrial loads such as steel mill loads. In this case study, the names of the feeders are Zone 1, Zone 2, Zone 3, Zone 4, Zone 5, Zone 5, Zone 6, Fertilizer 1, and Fertilizer 2 respectively. The single line diagram of case study area is shown in Fig. 4.

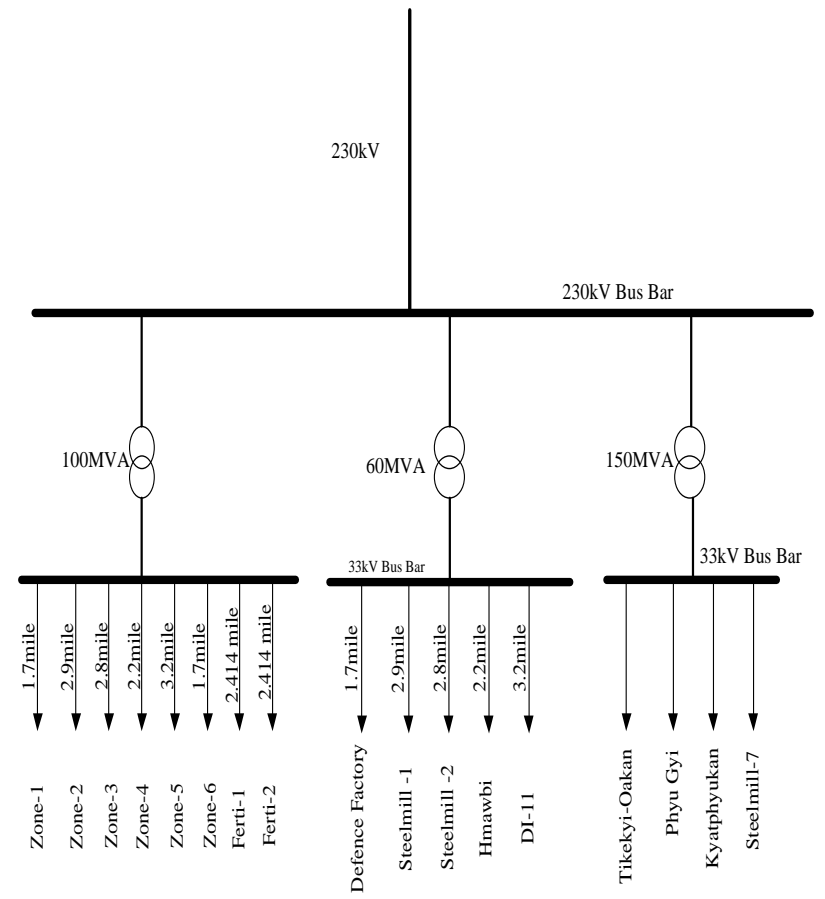

Fig. 4. Single line diagram of case study area.

\section{MODELLING OF PROPOSED SYSTEM WITH DVR}

The demand power of eight feeders for a typical day in the existing system of case study area is shown in Fig.5. According to this load demand graph, power consumption of the system is rising during 8 am to $4 \mathrm{pm}$ in the peak hour of the day. Maximum load consumption is between 11 am to 1 pm as per the graph.

The parameters of the simulation model for the existing system of the case study area are tabulated in Table I. This table includes the active power, reactive power and line length of each feeder for the case study area. Among the eight feeders, Zone 1, Zone 2 and Zone 3 have the highest load demand. Fertilizer 1 and Fertilizer 2 have the minimum value of the active and reactive power. These data are collected from Myaungtagar Industrial Distribution Substation base on the load consumption of May, 2018.

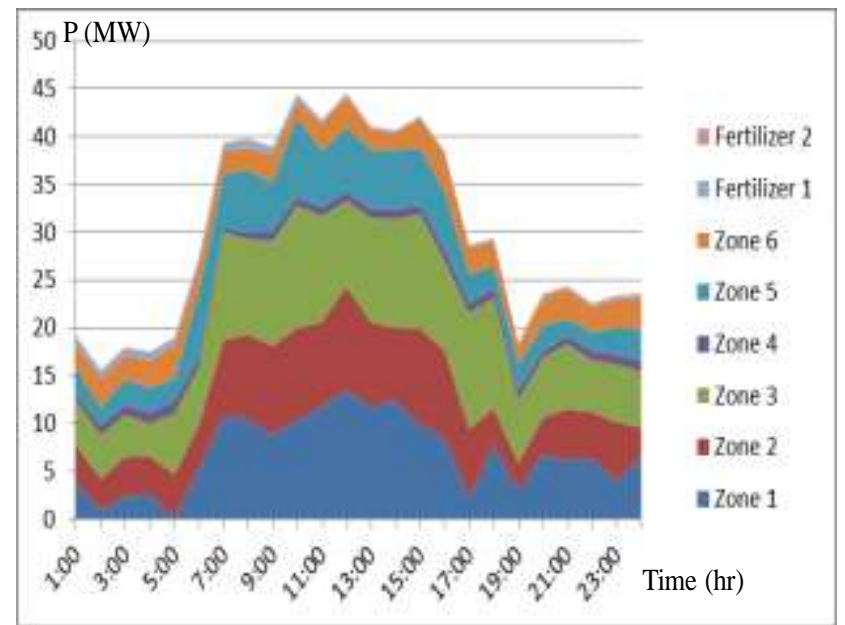

Fig. 5. Demand power of eight feeders for a typical day

TABLE I. PARAMETER OF SIMULATION MODEL

\begin{tabular}{|l|l|l|l|}
\hline Feeders & $\begin{array}{l}\text { Line Length } \\
\text { (km) }\end{array}$ & $\begin{array}{l}\text { Reactive powers } \\
\text { (MVAR) }\end{array}$ & $\begin{array}{l}\text { Active } \\
\text { powers } \\
\text { (MW) }\end{array}$ \\
\hline Zone 1 & 2.735885 & 3.65998 & 6.89708 \\
\hline Zone 2 & 4.6671 & 4.80004 & 6.36667 \\
\hline Zone 3 & 4.50616 & 4.874777 & 8.30833 \\
\hline Zone 4 & 3.540557 & 0.72029 & 0.93333 \\
\hline Zone 5 & 5.1499 & 3.33267 & 4.25833 \\
\hline Zone 6 & 2.73588 & 1.91355 & 2.75 \\
\hline Ferti 1 & 2.41402 & 0.2179 & 0.45 \\
\hline Ferti 2 & 2.41402 & 0.0605 & 0.1458 \\
\hline
\end{tabular}

The modelling of the existing system when fault occurs at the load side is shown in Fig.6. The case study area of the industrial distribution system source voltage $230 \mathrm{kV}$ is connected with $230 \mathrm{kV} / 33 \mathrm{kV}$ step down transformer. The outgoing of the step down transformer distribute the voltage for the eight feeders.

\section{Performance ANAlysis For SAg/Swell COMPENSATION}

The performance analysis for the voltage sag/swell simulation of modeling the existing system, we will consider two options for the voltage sag condition, the system have various fault conditions occurs at the load side and for the voltage swell condition, the capacitive load is connected to the system. 
JAREE-Journal on Advance Research in Electrical Engineering Volume3, Number 2, October 2019

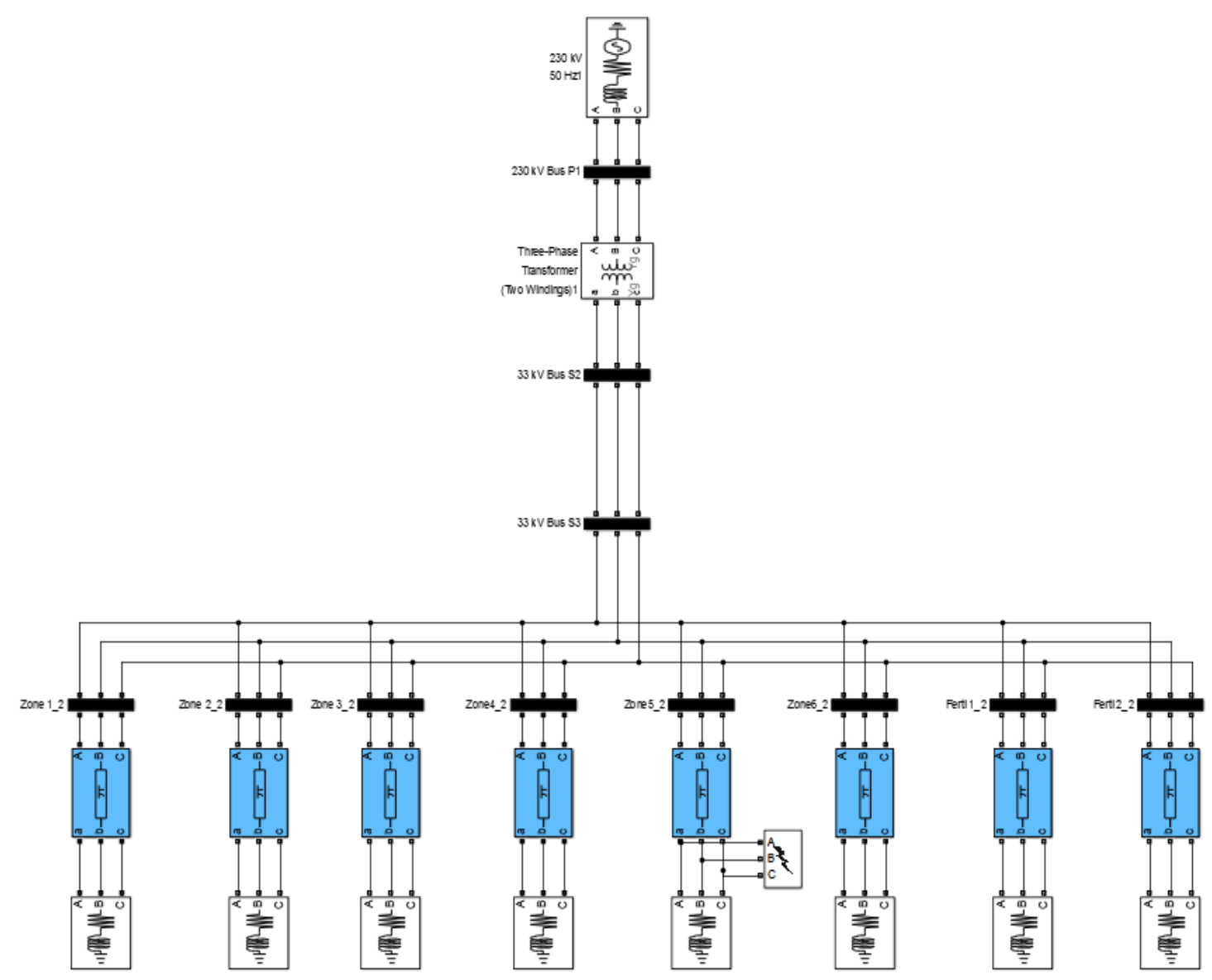

Fig. 6. Modelling of existing system with fault at load side

For the voltage sag condition, the fault is applied at Zone 5 which is the longest line length and average load among the feeders of the system. Therefore, it has the most chance for the occurrence of fault. For the voltage swell condition, capacitive load, 50MVAR is attached at $33 \mathrm{kV}$ transformer side in parallel with the load feeder.

When the system is suffer from the various fault conditions, the voltage profiles of the existing system are shown in Fig .7, Fig.8, Fig.9 and Fig.10. The fault is occurred at $0.5 \mathrm{sec}$ and the system voltage decreases to lower than $33 \mathrm{kV}$.

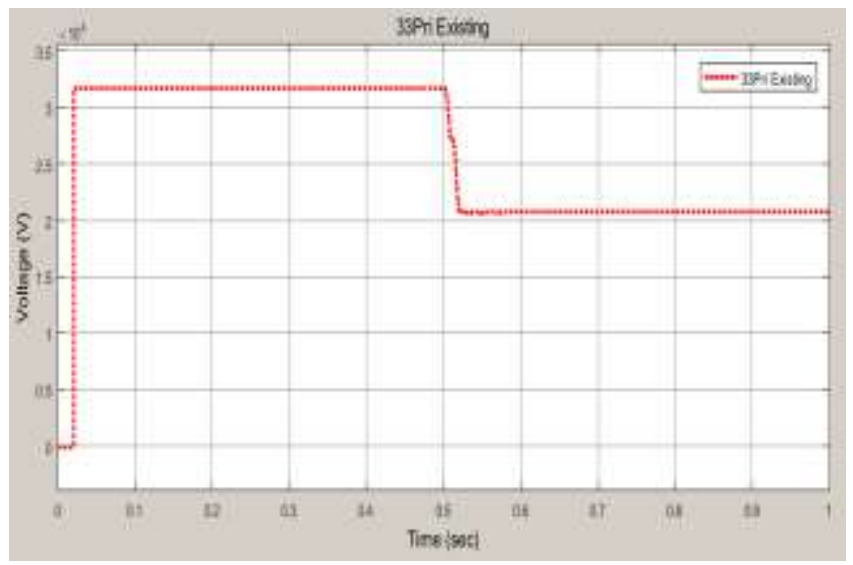

Fig. 7. Voltage profile of the system when single line to ground fault occurs

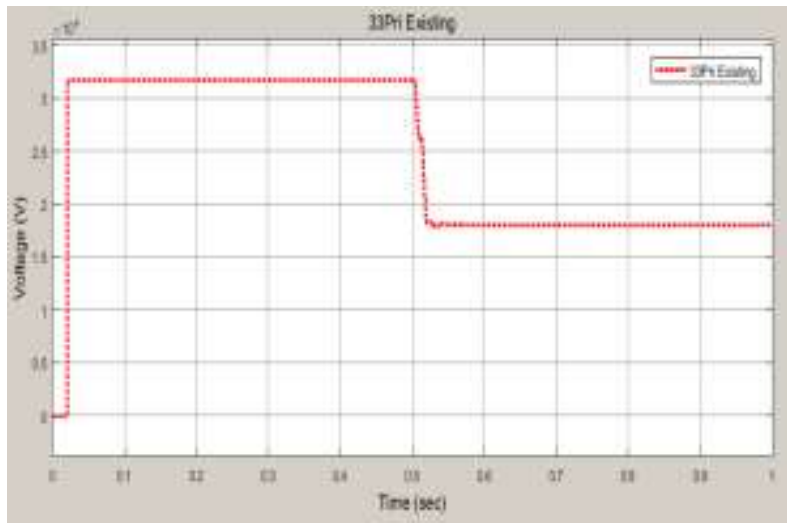

Fig. 8. Voltage profile of the system when double line to ground fault occurs

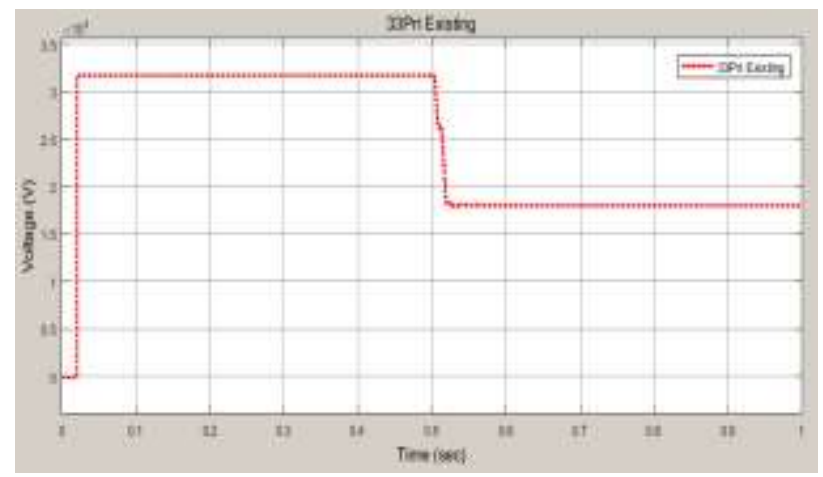

Fig. 9. Voltage profile of the system when line to line fault occurs 
JAREE-Journal on Advance Research in Electrical Engineering Volume3, Number 2, October 2019

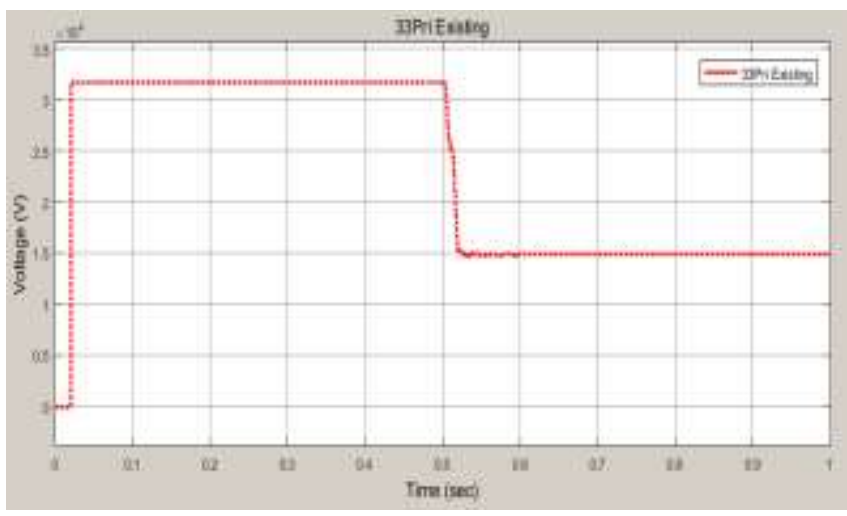

Fig. 10. Voltage profile of the system when three phase fault occurs

When the capacitive load is connected, the voltage profile of the system is shown in Fig. 11. When the capacitive load is connected at $0.5 \mathrm{sec}$ and the system voltage is increase from $33 \mathrm{kV}$ to $34.83 \mathrm{kV}$.

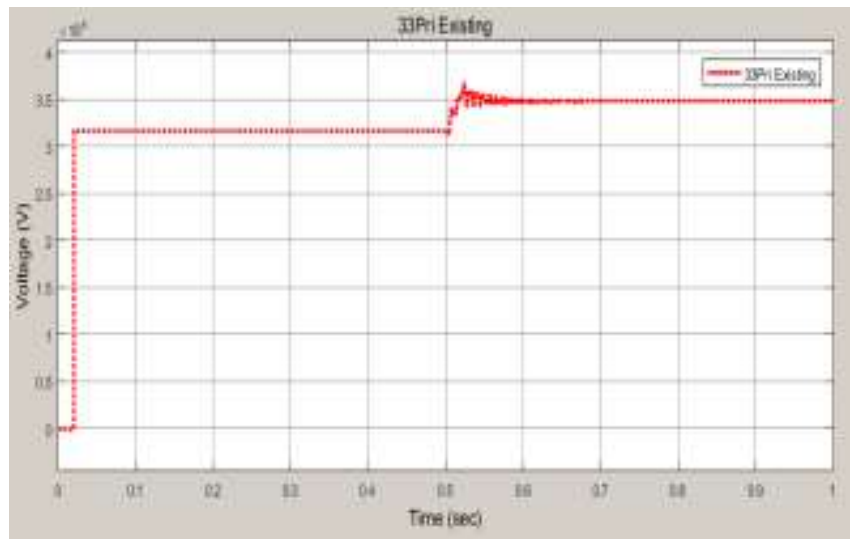

Fig. 11. Voltage profile of the system when the capacitive load is connected
To compensate the voltage sag and swell condition, modelling of the DVR is constructed in the existing system. Table II shows the system data of the DVR model.

TABLE II. SYSTEM DATA FOR DVR

\begin{tabular}{|l|l|}
\hline System Voltage & $\mathbf{3 3 k} \mathbf{}$ \\
\hline Series transformer turns ratio & $1: 3$ \\
\hline DC link Voltage & $44.567 \mathrm{kV}$ \\
\hline Filter Inductance & $94 \mathrm{mH}$ \\
\hline Total active power & $30.10954 \mathrm{MW}$ \\
\hline Total reactive power & 19.57971 MVAR \\
\hline
\end{tabular}

Fig. 12 shows Existing System is connected with DVR when fault occurs at load side. DVR is connected in series with $33 \mathrm{kV}$ source side and $33 \mathrm{kV}$ load side of the system via $25 \mathrm{MVA}, 33 \mathrm{kV} / 11 \mathrm{kV}$ three number of single phase transformer. The secondary side of these single phase transformer are connected with voltage source converter (VSC). DC terminal of Voltage Source Converter (VSC) are connected with Battery.

A DVR can compensate the voltage drop or voltage swell across a load by injecting or absorption a voltage through a series transformer with the source voltage. Voltage Source Converter (VSC) is used with hysteresis control for this purpose.

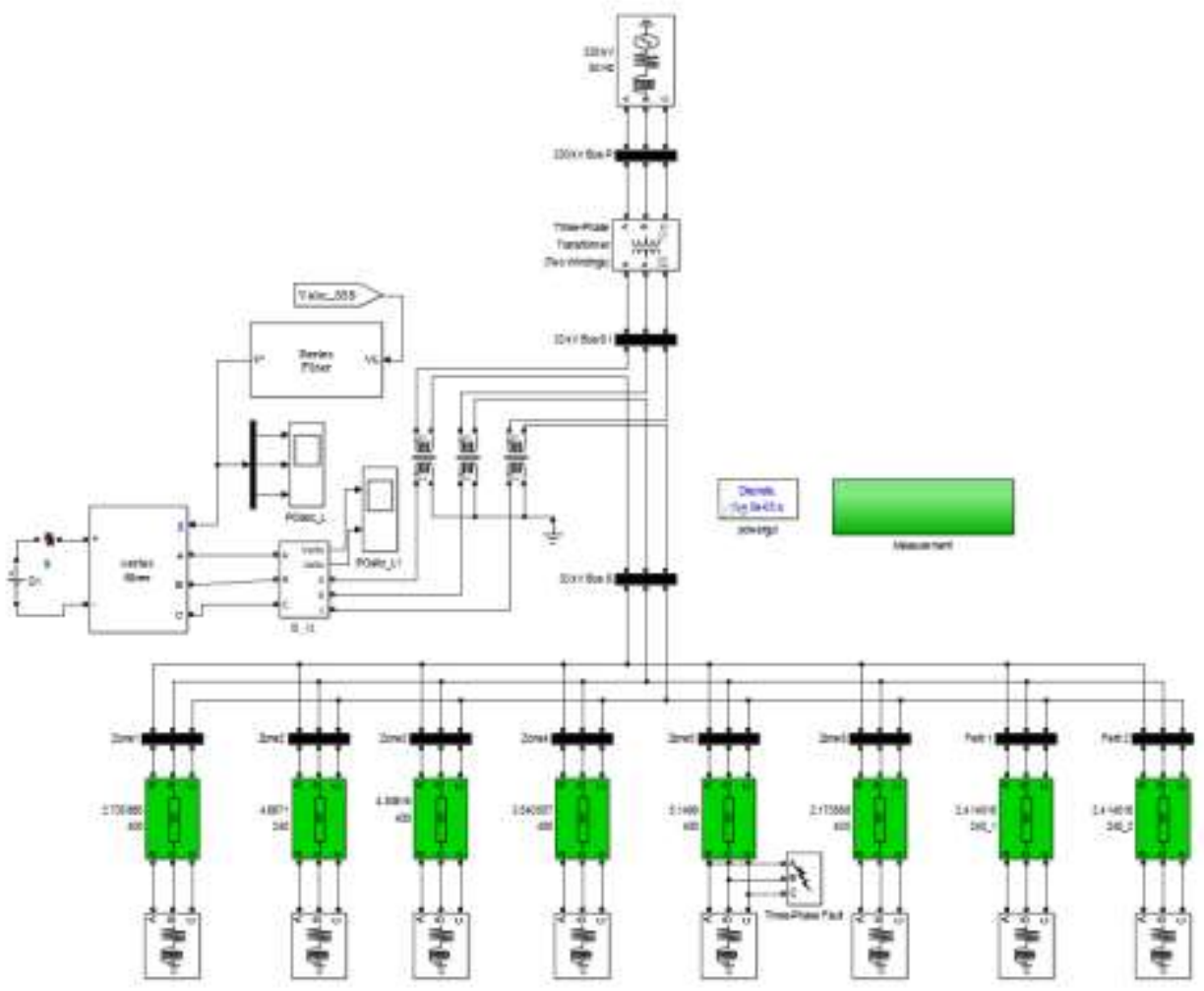

Fig. 12. Existing system is connected with DVR when fault occurs at load side 
Fig. 13 describe the modelling of Hysteresis controller. In this control, control signal is produced by using error signal which get from the comparing reference voltage and actual voltage with Hysteresis control .Voltage Source Converter (VSC) is operated by the controlled signal which is get from the Hysteresis control.

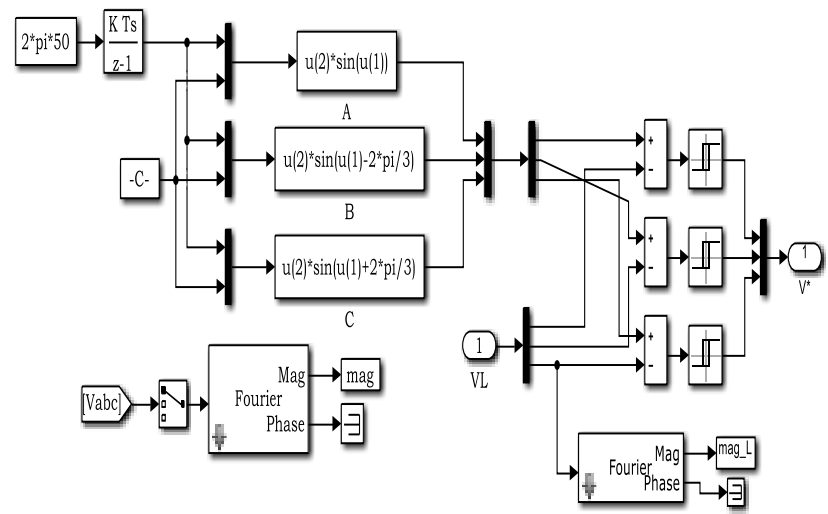

Fig. 13. Modelling of hysteresis controller

When various fault conditions occurs in the existing system, the voltage profiles with and without DVR are shown in Fig. 14, Fig.15, Fig.16, and Fig. 17.

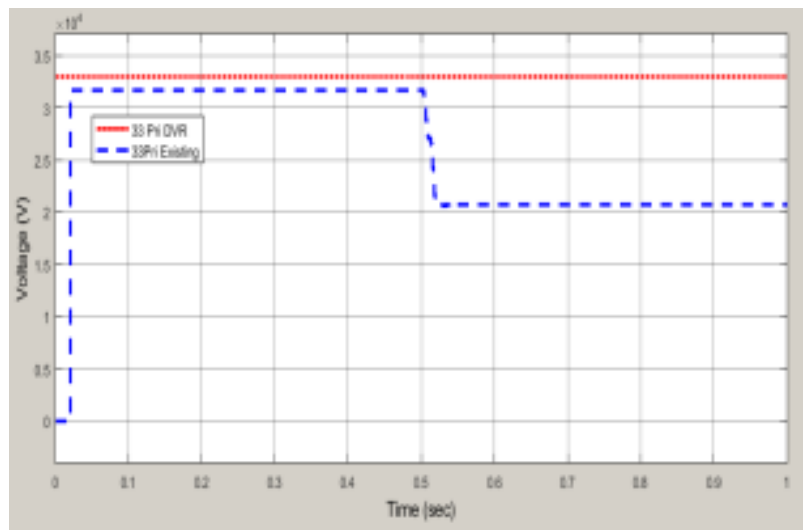

Fig. 14. With and without DVR voltage profile of the system when single line to ground fault occurs

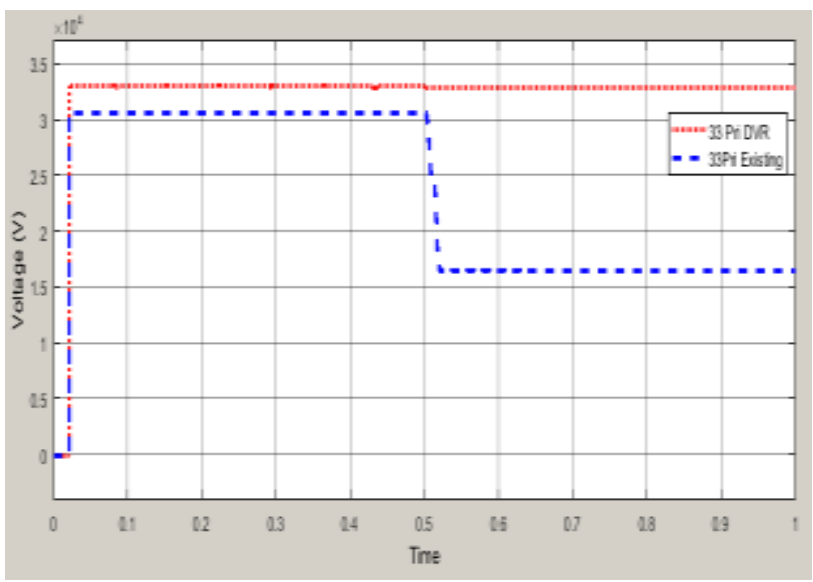

Fig. 15. With and without DVR voltage profile of the system when double line to ground fault occurs

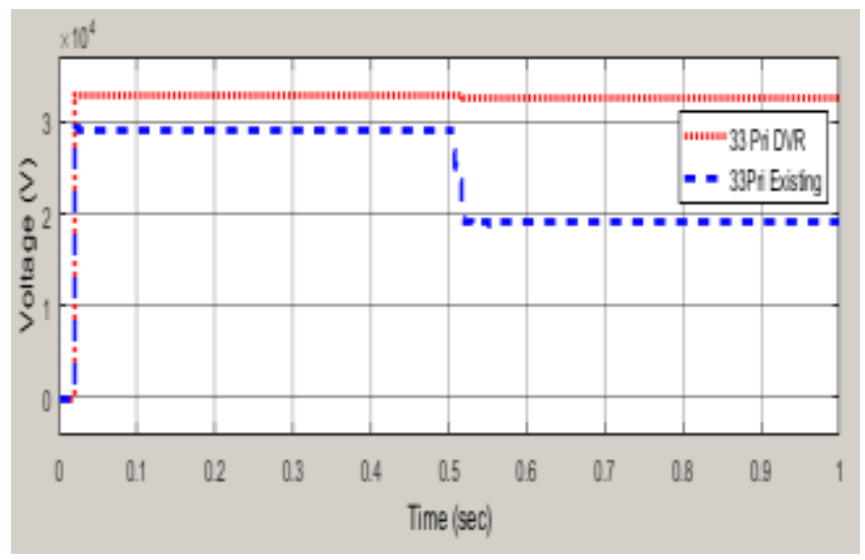

Fig. 16. With and without DVR voltage profile of the system when line to line fault occurs

When capacitive load is connected in the proposed system, the voltage profile with and without DVR is shown in Fig.18. When DVR is connected with the existing system, the voltage profile is better than without DVR of the system.

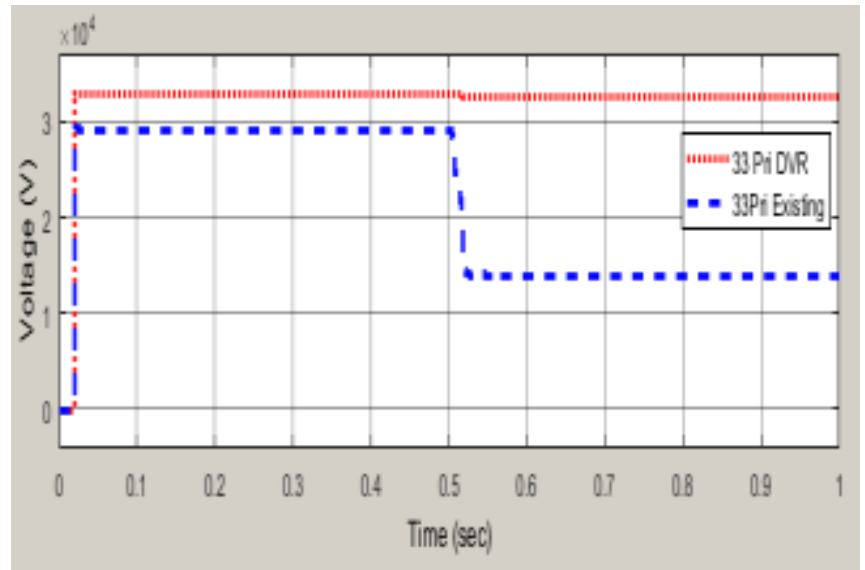

Fig. 17. With and without DVR voltage profile of the system when three phase fault occurs

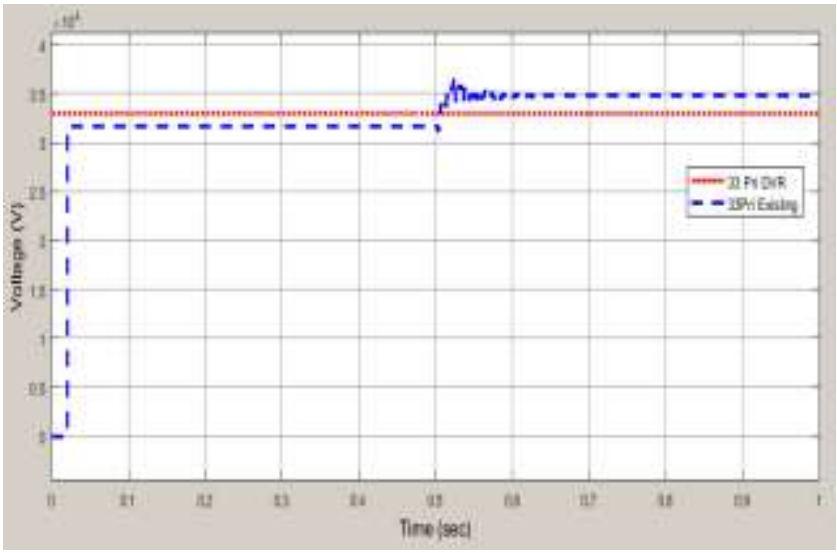

Fig. 18. With and without DVR voltage profile of the system when capacitive load is connected

In this portion, the voltage variation of existing system is analyzed due to the various types of faults such as three phase fault, single line to ground fault, double line to ground fault, line to line fault and capacitive connection. This simulation results with and without DVR in the existing system are tabulated in Table III. 
JAREE-Journal on Advance Research in Electrical Engineering Volume3, Number 2, October 2019

TABle III. Simulation Results Of EXISTING System With AND WITHOUT DVR UNDER FAULT CONDITON

\begin{tabular}{|c|c|c|}
\hline \multirow{2}{*}{ Fault Type } & \multicolumn{2}{|c|}{$33 k \mathrm{~V}$ source side } \\
\hline & Without DVR & With DVR \\
\hline Three Phase Fault & 14.119 & 32.855 \\
\hline Single Line to Ground Fault & 19.346 & 32.908 \\
\hline DL-G Fault & 16.528 & 32.855 \\
\hline Line to Line Fault & 19.1855 & 32.8819 \\
\hline Capacitive Load Connected & 35.272 & 32.985 \\
\hline
\end{tabular}

\section{VIII.CONCLUSION}

The modeling and simulation of a DVR for voltage sag/swell mitigation in industrial distribution system is presented in this paper. Myaungtagar Substation is chosen as case study area where the steel mills are the main loads and the voltage sag/swell is the main problems.

Therefore, economical loss and degradation in power quality result due to these voltage deviations. In this paper, DVR is used as a voltage sag/swell mitigation device and use to protect the sensitive loads in the system. The simulation result shows that the voltage sag/swell in the system can be fully mitigated by using DVR. Therefore, the dynamic voltage restorer presented in this paper is efficient and reliable for mitigation of voltage sag/swell in the industrial distribution system.

\section{REFERENCES}

[1] S.Saravanan1, M.Solaimanigandan2, T.Tharaneetharan3, V.Varunraj4. Dynamic Voltage Restorer for Distribution System, International Journal of Engineering Research and Development eISSN: 2278-067X, p-ISSN: 2278-800X, Volume 7, Issue 1 (May 2013), PP. 14-24.

[2] Bhim Singh, Ambrish Chandra, Kamal Al-Haddad. Power Quality Problems And Mitigation Techniques, 2015.

[3] Sanjay Haribhai Chaudhary, Mr. Gaurav gangil. Mitigation of voltage sag/swell using Dynamic Voltage Restorer (DVR), IOSR Journal of Electrical and Electronics Engineering (IOSR-JEEE) e-ISSN: 22781676,p-ISSN: 2320-3331, Volume 8, Issue 4 (Nov. - Dec. 2013), PP 21-38.

[4] Sandeep Kumar N. Power Quality Issues and its Mitigation Techniques, 2012-2014

[5] Roger C. Dugan, Mark F. Mc Granaghan, Surya Santoso, H. Wayne Beaty. Electrical Power System Quality, 2004

[6] Dev Kumar Taram. Power Quality Improvement Using Dynamic Voltage Restorer (DVR), 2015.

[7] T.Devaraju1, V. C. Veera Reddy and M. Vijaya Kumar. Performance of DVR under different voltage sag and swell conditions, ARPN Journal of Engineering and Applied Sciences, ISSN 1819-6608, VOL. 5, NO. 10, OCTOBER 2010 